\title{
The XIVth Century Cemetery of Castel San Pietro (Bologna, Italy)
}

\author{
F. Bertoldi ${ }^{1}$, C. Sisalli, G. Buccheri, M. Librenti ${ }^{1}$, A. Cianciosi, R. Cameriere ${ }^{2}$ \\ 1 Università Ca' Foscari, Venezia, Italy, Dipartimento di Studi Umanistici. E-mail: francescabertoldi@hotmail.com \\ 2 Institute of Legal Medicine, University of Macerata, Macerata, Italy
}

\section{KEYWORDS: Late Middle Age, cemetery, age determination.}

\section{Introduction}

The excavation area of this XVIth century cemetery, of which we present a preliminary study, extends over that previously occupied by the cinema-theatre Bios, now transformed into private dwellings and in an archaeological area open to the public. This place was already known in the XVIIIth century beacuse of the discovery of an inscription in the area of a chapel dedicated to $S$. Peter, built in the XIVth century and demolished in the XIXth century.After a decade of abandonment the archaeological soundings and the excavation performed by the Soprintendenza per i Beni Archeologici dell'Emilia Romagna with the help of the Gruppo per la Valorizzazione della Valle del Sillaro took place between 1997 and 1999 and allowed the discovery of a late antiquity basilical structure transformed during the Early Middle Ages (Ortalli, 2003). The Late medieval phase is testified by a large cemetery in which 176 individuals ( 140 adults, 53 males, 47 females, 76 of undetermined sex and 36 juveniles) have been buried (graphs 1-4 show the paleodemographical data of our sample). We can notice that the sub-adult sample, representing $20 \%$ of the total number of subjects recovered, is mostly reprsented by individuals aged between 10 and 15 years, with few newborns, infants and children below 10 years. The adult sample is unfortunately represented in many cases $(43 \%)$ by subjects too fragmented or badly preserved to allow a reliable sex diagnosis, however for those who could be correctly sexed males were $30 \%$ and females $27 \%$ of the total.Age at death of adults shows that females had a marked peak of mortality between 18 and 25, relevant also for males, which however tend to reach older ages. In order to verify our anthropological diagnosis of age at death through conventional methods, we analysed some samples applying the Cameriere dental method for age determination (Cameriere et al., 2006, 2007 a,b; De Luca et al., 2010) and the results of both our evaluations are presented in Tab. 1. In addition the human sample buried in Castel San Pietro cemetery showed evidence of heavy physical labour, skeletal and dental pathologies such as trauma, malnutrition,

congenital anomalies, arthrosis, caries, parodontosis, calculus, ante-mortem loss of teeth and abscesses.

\begin{tabular}{|c|c|c|c|c|}
\hline TOMB & SEX & $\begin{array}{c}\text { Anthropological } \\
\text { age }\end{array}$ & $\begin{array}{l}\text { Dental } \\
\text { age }\end{array}$ & Range \\
\hline CSP 1 & $M$ & $\sim 40$ & 39 & $35-45$ \\
\hline CSP 2 & $F$ & $17-25$ & 24,1 & $17-25$ \\
\hline CSP 4 & $F$ & $17-25$ & 24,2 & $17-25$ \\
\hline CSP 5 & $M$ & $30-35$ & 30,6 & $30-45$ \\
\hline CSP 16 & $\mathrm{~F}$ & $25-35$ & 29,6 & $25-35$ \\
\hline CSP 17 & $F$ & $17-25$ & 19,25 & $17-25$ \\
\hline CSP 18 & $F$ & $25-35$ & 40,1 & $25-35$ \\
\hline CSP 20 & $F$ & $17-25$ & 21,1 & 17.25 \\
\hline CSP 21a & $M$ & $17-25$ & 18,4 & $17-25$ \\
\hline CSP 28 & $M$ & -35 & 40,8 & $30-35$ \\
\hline CSP 35 & $M$ & $\sim 35$ & 45,7 & $30-35$ \\
\hline CSP 42 & $F$ & $35-45$ & 47,31 & $35-45$ \\
\hline CSP 46 & $M$ & $45-50+$ & 56,5 & $45-55$ \\
\hline CSP 51 & $F$ & $25-35$ & 37,2 & $25-35$ \\
\hline CSP 54 & $M$ & $25-30$ & 26,2 & $25-30$ \\
\hline CSP 70 & $F$ & $35-45$ & 54,2 & $33-45$ \\
\hline
\end{tabular}


F. Bertoldi, C. Sisalli, G. Buccheri, M. Librenti,A. Cianciosi, R. Cameriere

\begin{tabular}{|l|l|r|r|r|}
\hline TOMB & SEX & $\begin{array}{c}\text { Anthropological } \\
\text { age }\end{array}$ & \multicolumn{1}{c|}{$\begin{array}{c}\text { Dental } \\
\text { age }\end{array}$} & Range \\
\hline CSP 90 & M & $17-25$ & 20,2 & $17-25$ \\
\hline CSP 93 & F & $17-25$ & 21,3 & $17-25$ \\
\hline CSP 115 & M & $33-45$ & 62,2 & $33-35$ \\
\hline CSP 161 & F & $33-45$ & 56,2 & $33-45$ \\
\hline
\end{tabular}

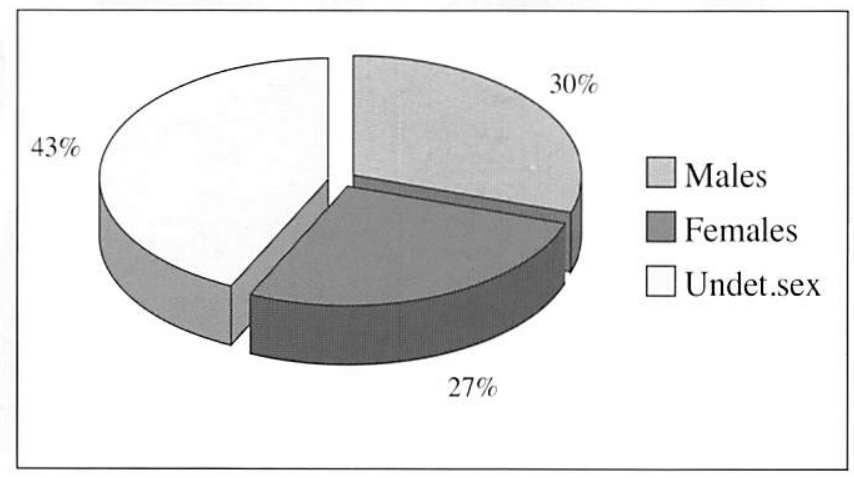

Graph 3. The sex distribution of the adult sample

Tab. 1. The results of evaluations about dental age and anthropological age.

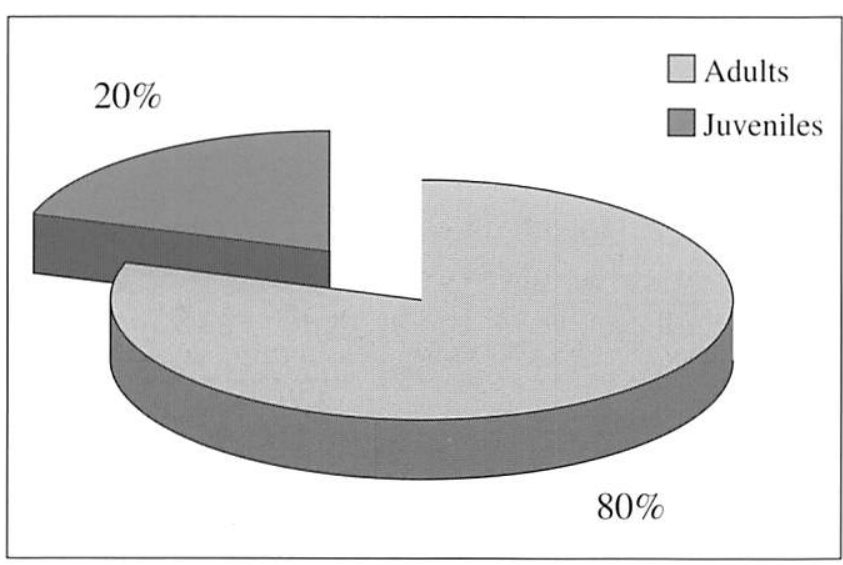

Graph 1. Adults and juveniles in the sample

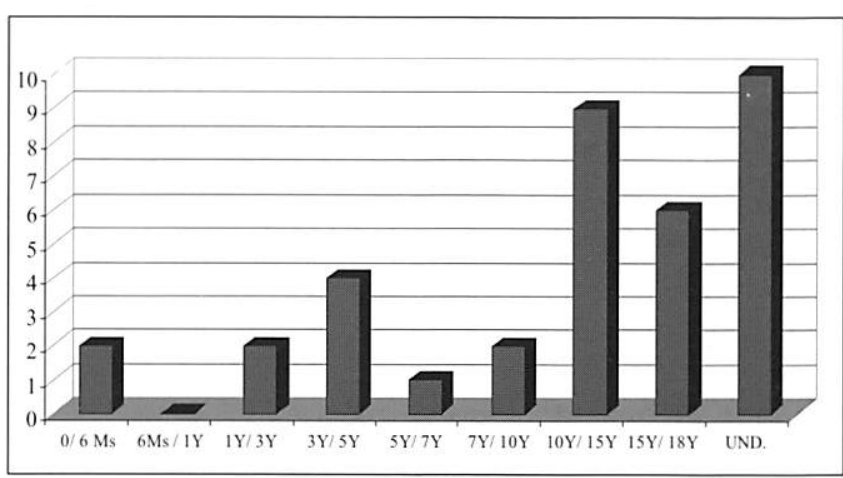

Graph 2. The age classes of the sub-adult sample

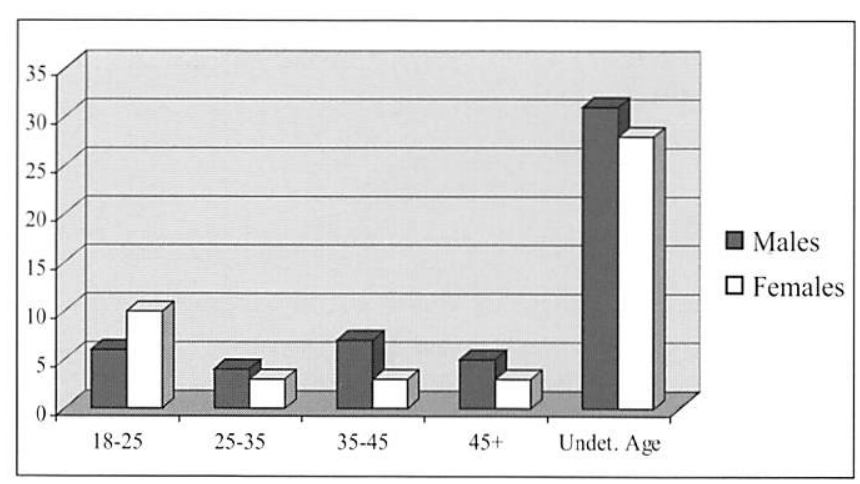

Graph 4. The age classes of the adult sample

\section{References}

Bertoldi F. 2009. Determinazione del sesso ed età alla morte. In: Mallegni F., Lippi B. (a cura di), Non Omnis Moriar, Roma: 31-57. Cameriere R., Brogi G., Ferrante L., Mirtella D.,Vultaggio C., Cingolani M., Fornaciari G. 2006. Reliability in age determination by pulp/tooth ratio in upper canines in skeletal remains. J. Forensic Sci., 51: 861-4.

Cameriere R., Ferrante L., Belcastro M.G., Bonfiglioli B., Rastelli E., Cingolani M. 2007. Age estimation by pulp/tooth ratio in canines by peri-apical X-rays.J. Forensic Sci., 52 (1): 166-70.

Cameriere R., Ferrante L., Belcastro M.G., Bonfiglioli B., Rastelli E., Cingolani M. 2007. Age estimation by pulp/tooth ratio in canines by mesial and vestibular peri-apical $X$-rays. J. Forensic Sci., 52(5): 1151-1155.

De Luca S.,Aleman I., Bertoldi F., Ferrante L., Mastrangelo P., Cingolani M., Cameriere R. 2010. Age estimation by tooth/ pulp ratio in canines by periapical $X$-rays: reliability in age determination of Spanish and Italian medieval skeletal remains. J.Archaeol. Sci., 37: 3048-3058.

Ortalli J. (a cura di) 2003. San Pietro prima del Castello. Gli scavi nell'area dell'ex-cinema teatro Bios a Castel san Pietro Terme (Bo). Firenze. 